\title{
Borderline Papillary Serous Tumour of the Peritoneum
}

\author{
Rahman MM', Azad MAK ${ }^{2}$, Ahmed N N $^{3}$, Rahman N N ${ }^{4}$ Hussain MR
}

Conflict of Interest: None

Received: 01 December 2016

Accepted: 02 December 2016

www.banglajol.info/index.php/JSSMC

\section{Key Words:}

Papillary, Borderline

\begin{abstract}
Abstr act
Primary borderline serous peritoneal tumour is a rare lesion found in the absence of ovarian pathology, in the presence of minimal ovarian involvement or in association with benign ovarian tumour. It is thought to arise from the mullerian system, which is embryologically derived from the coelomic and sub-coelomic mesenchyme, and therefore shares histologic similarities with ovarian serous tumours. Such tumours are mostly found in women of reproductive age group although cases have been reported for post-menopausal women. We report a case of a primary peritoneal borderline tumour diagnosed in a middle aged patient with lump and pain the upper abdomen in Shaheed Suhrawardy Medical College \& Hospital.
\end{abstract}

[J Shaheed Suhrawardy Med Coll 2016; 8(2): 69-72] DOI: http://dx.doi.org/10.3329/jssmc.v8i2.37247

\section{Introduction}

Primary borderline papillary serous tumour is a rare lesion, histologically indistinguishable from non-invasive peritoneal implants found in association with ovarian tumours of borderline malignancy. ${ }^{1}$ The recognition of a primary peritoneal tumour of borderline malignancy relies on the presence of either normal ovaries, ovaries containing a benign tumour or ovaries showing only minimal surface involvement. ${ }^{2}$ We report a case of primary peritoneal borderline tumour diagnosed in a 43 year old woman.

\section{Case Report}

A 43 year old lady presented with a lump and pain in her left upper abdomen. Menarche occurred at the age of 12 years. She had been on oral hormonal contraception for 10 years. She had vaginal term delivery seven years back. She had no family history of breast or ovarian disease.

1. Prof. Md. Mustafizur Rahman, Professor, Shaheed Suhrawardy Medical College Hospital, Dhaka.

2. Dr. Md. Abul Kalam Azad, Assistant Professor (Surgery), Shaheed Suhrawardy Medical College Hospital, Dhaka.

3. Dr. Nadim Ahmed, Senior Consultant (Surgery), Shaheed Suhrawardy Medical College Hospital, Dhaka.

4. Dr. Nazmin Rahman, Honorary Medical Officer, Department of Surgery, Shaheed Suhrawardy Medical College Hospital, Dhaka.

5. Dr. Muhammad Raquib Hussain, Assistant Registrar, Department of Surgery, Shaheed Suhrawardy Medical College Hospital, Dhaka.

Correspondence to: Dr. Nadim Ahmed, Senior Consultant (Surgery), Shaheed Suhrawardy Medical College Hospital, Dhaka.
She noticed the lump about four months back which was initially small but gradually increased in size. The lump was about $20 \mathrm{X} 15 \mathrm{~cm}$ in size, occupied the epigastric, left hypochondriac, left lumbar and umbilical region; firm in consistency; smooth surface; ill-defined margin; did not move with respiration (fig-3). The overlying skin was free but it was adherent to the underlying structures and immobile in all directions. Initially there was no pain, but the patient developed pain in the region of the lump which was intermittent, dull aching in nature but there were no aggravating factors. Her bladder and bowel habits were normal. Other she appeared clinically well with no jaundice, ascites, edema, lymphanenopathy. There were no organomegaly.

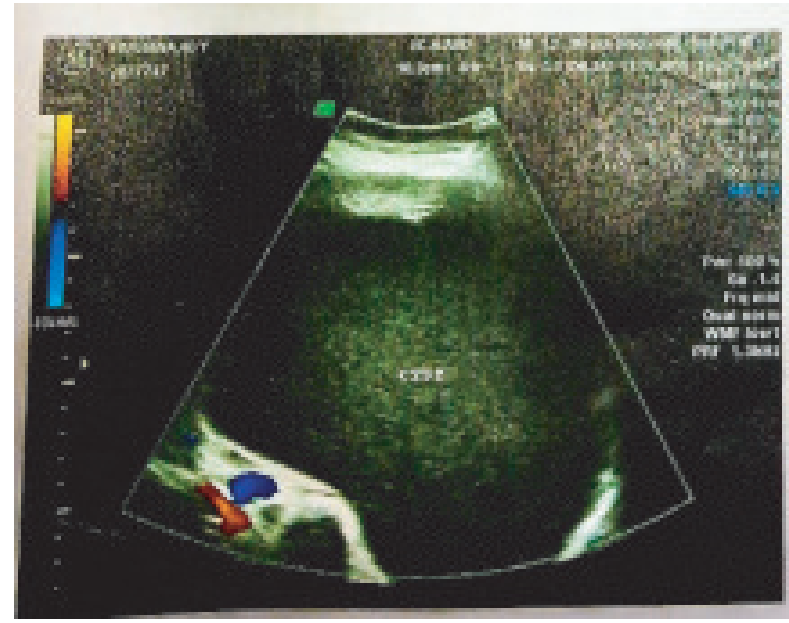

Fig-1: USG of whole abdomen 
Ultrasonogram (fig-2) of whole abdomen revealed a large cyst in upper abdomen measuring about 20.1X18.67X14.9 $\mathrm{cm}$ in upper abdomen at left hypochondriac region compressing and displacing left kidney downwards and towards right.

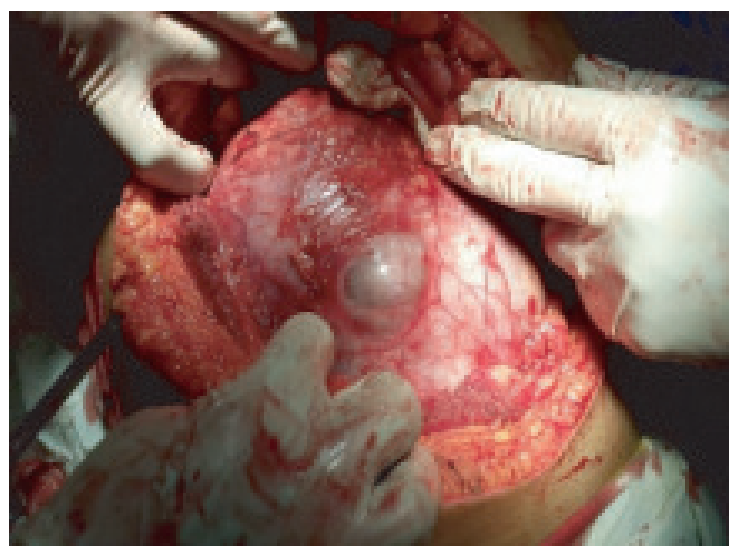

Fig-2: Per-operative appearance of cyst.

On 7th October 2015 during exploratory laparotomy a large cyst (fig-2) with tense wall was found in upper abdomen. The condition of intraabdominal organs and omentum were absolutely normal. As the cyst was difficult to remove intact, it was punctured and about two (02) liters of turbid fluid was sucked out. The sac wall was adherent to the left kidney and anterior surface of the pancreas. It was removed by blunt dissection and the specimen of the cyst wall was sent for histopathology

The post-operative period was uneventful. No wound infection occurred and the patient was discharged on 14th post- operative day after getting the histopathology report.

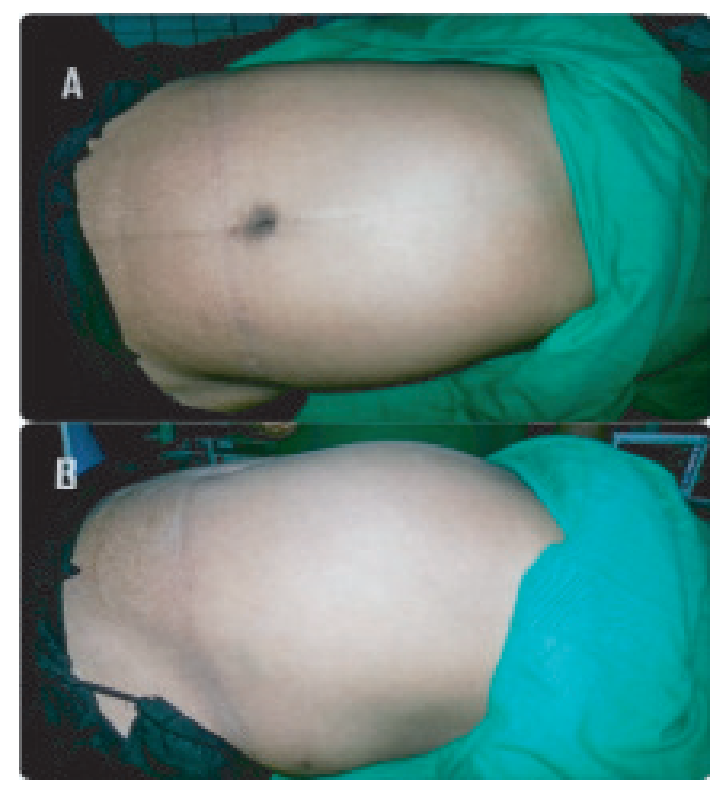

Fig-3: (a) top view (b) side view of abdomen
Upon gross examination (fig-4) the specimen consisted of $16 \times 12$ com grey white piece of cystic tissue. The wall was $1.2 \mathrm{~cm}$ thick. The cut surface showed a wall like tissue and ulcerated area. Microscopic sections revealed a neoplastic serous tumour, which was lined by stratified layersof atypical cuboidal cells showing glandular complexity, branching papillary fronds and focal stromal micro-invasion. Focal mitotic activity and areas of haemorrhage and necrosis were also present.

The final diagnosis was 'Borderline Papillary Serous Tumour of Peritoneum (low malignant potential)'

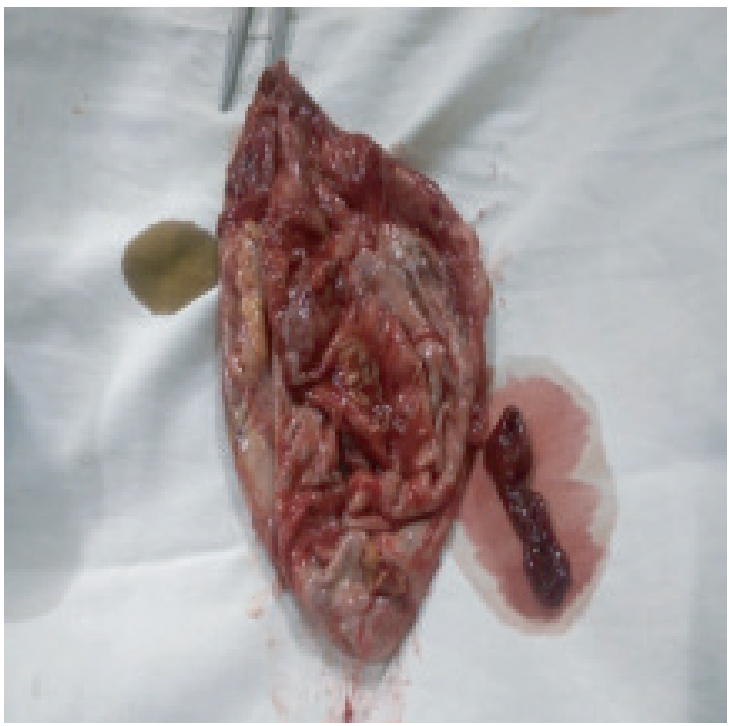

Fig-4: Resected specimen.

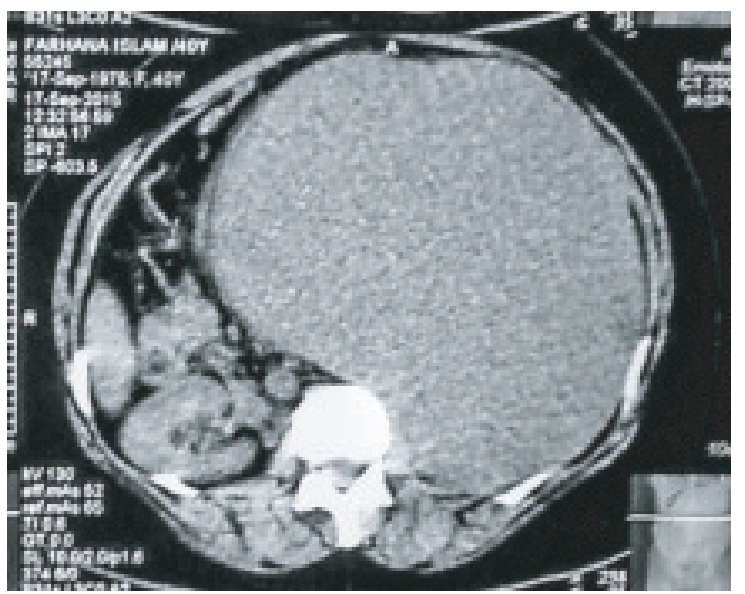

Fig-5: CT scan of abdomen

\section{Discussion}

Primary peritoneal neoplasms in the female may be mesothelial or mullerian in nature. The mullerian system is derived embryologically from a coelomic epithelium and a sub-coelomic mesenchyme. The adult derivative of these structures - surface epithelium of the ovary and 
peritoneum - retain a potential for mullerian differentiation, developing tumours that can be benign, of borderline malignancy or malignant. ${ }^{3}$

Primary peritoneal serous borderline tumour (PPSBT), also known as serous micro-papillomatosis of low malignant potential, is a rare proliferation of epithelial cells that can present as an incidental finding at laparotomy and raise concern for a primary ovarian tumour with peritoneal implants. The recognition of primary peritoneal tumour of borderline malignancy relies on the presence of normal ovaries, ovaries showing a benign tumour or ovaries having a minimal surface involvement. ${ }^{2}$ Before this term was coined, similar lesions had been noted as "atypical endosalpingiosis"4,5 or "primary papillary peritoneal neoplasia. ${ }^{6}$

At surgery, the gross characteristics of PPSBT have a variable appearance, with focal-to-diffuse lesions that may be miliary, granular, or nodular or may resemble adhesions. Blebs or cystic lesions have also been described. A dominant peritoneal nodule or cyst has been described in 4 cases. ${ }^{7,8}$

The microscopic features of these peritoneal/serosal foci have traditionally been divided into 2 categories: lesions with or without a prominent fibroblastic response surrounding the epithelial cell proliferation. ${ }^{11}$ Lesions with a prominent fibroblastic reaction appear "stuck on" to otherwise-normal serosa with an easily discerned demarcation between the reactive and normal serosal stroma. The epithelial component is entrapped within and often distorted by the surrounding stromal proliferation. If this distortion is severe, the lesion may contain individual cells and small solid clusters. The cells lack significant cytologic atypia and mitoses. Destructive stromal invasion is usually not identified. Lesions that lack a fibroblastic reaction consist of broad papillary groups of epithelial cells with mild-to-moderate nuclear atypia, either loosely attached to or detached from the peritoneal surface the cells constituting the papillae may be flat, cuboidal, or columnar with one to several layers of lining cells. The lining cells may detach from the surrounding stroma, forming "clefts" Psammoma bodies are quite often numerous and prominent among these lesions.

Only two large series of such lesions have been reported. Bell and Scully ${ }^{7}$ analysed 25 cases they designated "serous borderline tumours of peritoneum". Biscotti and Hart $^{8}$ studied 17 cases they reported as "peritoneal serous micropapillomatosis of low malignant potential".

The most commonly affected patients are women, usually of reproductive age group, but can also affect post- menopausal women. Clinical features often include abdominal/pelvic pain, amenorrhoea, chronic pelvic inflammatory disease, infertility, or small bowel obstruction. Most often the lesions are discovered incidentally during laparotomy. ${ }^{7,8}$

The risk factors for developing these tumours are not well known. Nulliparity, infertility and use of infertility drugs appear to increase the risk, while pregnancy, breast freeding and oral contraceptives seem to have a protective effect. ${ }^{9,10}$ The condition does not have an association with hereditary ovarian cancers. ${ }^{10}$

Regarding the treatment, a conservative surgical approach is possibly with preservation of the uterus and ovaries in young women, once the presence of an associated primary ovarian tumour has been excluded. In older women all visible lesions should be removed, as long as this does not imply removal of major organs, because of the risk of recurrence or transformation to lowgrade carcinoma. Adjuvant therapy is not indicated. 2,7,8

The prognosis for patients with peritoneal borderline tumours is very good ${ }^{7,8}$ with a $95 \%$ survival rate similar to the survival reported for women with ovarian serous borderline tumours and non-invasive peritoneal implants. Recurrence has been reported by Biscotti et $\mathrm{al}^{8}$, in 2 out of the 17 patients. However, they were both alive about 16 years after their first diagnosis. However, a small portion of the patients with residual disease may develop small bowel obstruction.

\section{Conclusion}

Borderline papillary serous tumour of the peritoneum is a very rare condition, often found in women of reproductive age group, having similar histological features with that of ovarian serous epithelial tumours. The exact aetiopathogenesis still remains unknown, and the diagnosis is incidentally established during laparotomy followed by histopathology, and has a good prognosis. This study recommends that, although rare, it is important for surgeons and gynaecologists to bear in mind the possibility of such tumours, especially when diagnosing women of reproductive age group with abdominal pain and/or lump.

\section{Refere nces}

1. Hart w.R.: "Pathology of malignant and borderline epithelial tumours of ovary". In: coppleston M. (ed.). Gynaecologic oncology. Fundamental Principles and Clinical Practice: bol. 2, New York, Chuchill-Livingstone, 1981, 633.

2. Biron-Shental T., Klein Z, Eldestein E., Altaras M., Fishman A.: "Primary peritoneal borderline tumours: histologic features and prognosis". Cancer. 1988, 62. 2212.

3. Fox H.: "Primary neoplasia of the female peritoneum". Histopathology, 1993, 23, 103 
4. Zinsser KR, Wheeler JE. Endosalpingiosis in the omentum: a study of autopsy and surgical material. Am J Surg Pathol. 1982;6:109-117.

5. Dallenbach-Helleweg G. Atypical endosalpingiosis: a case report with consideration of the differential diagnosis of glandular subperitoneal inclusions. Pathol Res Pract. 1987; 182: 180-182.

6. Genadry R, Poliakoff S, Rotmensch J, et al. Primary, papillary peritoneal neoplasia. Obstet Gynecol. 1981; 58:730-734.

7. Bell DA, Scully RE. Serous borderline tumors of the peritoneum. Am J Surg Pathol. 1990;14:230-239.
8. Biscotti CV, Hart WR. Peritoneal serous micropapillomatosis of low malignant potential (serous borderline tumors of the peritoneum): a clinicopathologic study of 17 cases. Am J Surg Pathol. 1992;16:467-475.

9. Trope C.,Karen J.: "Management of borderline tumours of the ovary: state of art". Semin. Oncol., 1998, 25,372.

10. Trimble C.L., Trimble E.: "Management of epithelial ovarian tumors of low malignant potential". Gynaecol. Oncol., 1994, 55, 52.

11. Bell DA, Weinstock MA, Scully RE. Peritoneal implants of ovarian serous borderline tumours: histologic features and prognosis. Cancer 1988;63:2212-2222. 